\title{
Manufacturer's Collaborative Business Strategy with Two Different Reverse Channels in a Closed-Loop Supply Chain
}

\author{
Sungwook Yoon $(\mathbb{D}$ and Sukjae Jeong \\ Business School, Kwangwoon University, 26 Kwangwoon-gil (447-1, Wolgye-dong), Nowon-Gu, Seoul 139-701, Republic of Korea \\ Correspondence should be addressed to Sukjae Jeong; sjjeong@kw.ac.kr
}

Received 22 April 2021; Revised 4 July 2021; Accepted 10 August 2021; Published 24 August 2021

Academic Editor: Lei Xie

Copyright (c) 2021 Sungwook Yoon and Sukjae Jeong. This is an open access article distributed under the Creative Commons Attribution License, which permits unrestricted use, distribution, and reproduction in any medium, provided the original work is properly cited.

\begin{abstract}
Reuse of products has become increasingly critical to reduce manufacturing costs and revitalize the new product market. With two different investment perspectives, manufacturers cooperate with retailers and recyclers to collect products from customers. By investing in the retailer, manufacturers gain an opportunity to sell new products, whereas by investing in the recycler, manufacturers can reduce production costs through remanufacturing. Therefore, manufacturers must determine the appropriate investment strategies to be applied to the two channels by analyzing the trade-offs between these opportunities. For this purpose, we discuss three investment strategies: Revenue-Sharing Investment, Direct Subsidy per Unit Returned Cartridge, and Hybrid Investment. The system dynamics model is used to construct scenarios of various investment strategies used by the manufacturer with the collection partners and analyze the corresponding changes in the revenues of the manufacturer. The results indicate that the application of the revenue-sharing strategy and the hybrid strategy to support retailers and recyclers is effective in increasing manufacturer profit. More specifically, by considering the hybrid investment strategy of revenue-sharing investment and the direct subsidy per unit returned cartridge for the recycler, the manufacturer can simultaneously avoid excess investment by the recycler and promote return activities through the recycler.
\end{abstract}

\section{Introduction}

Closed-loop supply chains (CLSCs) focus on collecting used products from customers and reusing them to generate value. This loop consists of a traditional forward supply chain (FSC), in which products are sold via retailers, and a reverse supply chain (RSC), in which used products are returned via reverse channels [1].

The value of the RSC is threefold. First, the process of remanufacturing used products reduces the requirement for raw materials inherent to traditional production processes and could ultimately lower manufacturing costs. Second, partners in the supply chain, such as retailers and manufacturers, can acquire an opportunity to sell new products to the customers who participate in the return activity. Third, for auxiliary and consumable products that depend on another device, such as ink cartridges for a printer, the manufacturer can encourage customers to buy new products rather than refurbish or refill the used ones when the RSC is employed.

A variety of reverse channel formats are currently deployed by manufacturers [2]. In some cases, manufacturers collect their used products directly from customers. For instance, Xerox Corporation provides prepaid boxes for customers to use to return cartridges. Manufacturers utilize retailers as another reverse channel to collect used products. For instance, Eastman Kodak Company retrieves single-use cameras from large retailers. Manufacturers also often enter into contracts with recycling companies, such as GENCO Distribution System, to collect used products.

Although the manufacturer takes advantage of both partners to increase the collection of used products, the expectations of the manufacturer regarding the collection activities of the two partners differ. The manufacturer expects retailers to not only reclaim more used products from customers who visit the retail market with used products but 
also create opportunities to sell new products when used products are returned. By contrast, the manufacturer expects the recycler to collect used products from customers who did not visit the retail market and prefer discarding to returning. Then, the manufacturer uses the returned products in a remanufacturing process, and the finished products are distributed through forward supply chain channels. Such activities reduce the requirements for raw materials associated with traditional production processes and ultimately lower manufacturing costs. The manufacturer also recognizes that the return activity of the retailer does not entirely depend on the manufacturer's subsidy, because the retailer invests in customers to increase sales opportunities for new products. However, the volume of cartridges collected by the recycler is proportional to its ability to visit customers within a given period, which in turn is determined by the reward provided by the manufacturer.

Manufacturers would like to increase the return rate of used products by sharing with their partners (recycler and retailer) the benefits generated from the CLSC channel. Recycler would expect high compensation for active recycling activities and the retailer would expect compensation from manufacturers for discounted prices when selling new products. The results of this study will contribute to finding the best way for manufacturers to share benefits with both partners on CLSC revenue and ways to share benefits.

For effective analysis, we developed a CLSC model comprising a manufacturer, a retailer, and a recycler using the system dynamics model. The developed model configures various scenarios based on the manufacturer's investment strategies to promote the collection activity of collection partners and encourage customers to return used products more often. We also discuss which investment strategy the manufacturer should consider for the two channels based on the trade-offs between the opportunity to sell new products by investing in the retailer and the reduction in production costs created by investing in the recycler.

The rest of this paper is organized as follows. We review the related literature in the next section. The developed simulation model of the CLSC, including the customer, manufacturer, retailer, and recycler, is described in Section 3. We provide the experimental results and the analysis of the manufacturer's investment strategies based on the model in Section 4. Finally, concluding remarks and suggested directions for further research are discussed in Section 5.

\section{Literature Review}

The CLSC is a model that integrates the FSC with its cycle of production, distribution, and delivery to customers, and the RSC with its cycle of collection, delivery, remanufacturing, and resale of used products [3]. Thus, the CLSC not only creates profit for corporations but also supports efforts to protect the natural environment. This mechanism, however, involves many factors, including the relationships among supply chain participants, price decisions, product retrieval strategy, regulations, and environmental restrictions, which in turn complicate decision-making by the participants [4].
This complexity has attracted researchers and field workers to study the subject for the past twenty years [1].

Savaskan and Van Wassenhove [5] studied an RSC with a single manufacturer and two retailers in a relationship of retail price competition. The study formulated and analyzed two decentralized CLSC models: (1) Model DD (decentralized direct collection), in which the manufacturer collects used products directly from the customers; and (2) Model DI (decentralized indirect collection), in which the manufacturer contracts with the retailers to collect used products indirectly.

The most fundamental issues in a CLSC are the decisionmaking factors that influence customer willingness. Prior to 2004 , studies focused on decision-making by a central decision-maker or on optimizing the total system profit [6-9]; the trend evolved under Savaskan and Van Wassenhove [5]; who used game theory to solve problems among independent agents such as manufacturers and retailers. Mafakheri and Nasiri [10] introduced a typical leader-follower (Stackelberg) strategic decision-making game problem observed between manufacturers and retailers. In this problem, retailers determine the appropriate level of return incentives for customers based on the expected revenue shared by the manufacturer. Simultaneously, the manufacturer assumes that it can predict the behavior of the retailers and adjusts its revenue-sharing strategy to maximize its own profits.

Saha et al. [11] conducted a study at CLSC on the Reward driven policy to return used products from customers. They considered a single forward supply channel and three reverse supply channels. In the presented models, they analyzed how the maximum amount of recovery compensation that the retailer and recycler could pay to the customer and how it would affect the selling price of the product on the models if used products are recovered from the customer through both.

Studies have also analyzed how the main drivers that facilitate the return of used products influence the performance of the supply chain partners. Savaskan et al. [2] studied the impact of the choice of RSC on the forward channel decision and rate of the product return. Savaskan and Van Wassenhove [5] studied an RSC structure in which retailers compete; in this model, manufacturers directly collecting used products and indirectly collecting them through retailers were observed, and the impact of each method on wholesale and retail prices as well as the used products' return rate was analyzed. Yoon and Jeong [12] proposed three procedures for implementing contracts between the manufacturer and retailer to maximize both individual and total profits in an RSC environment.

Nielsen et al., [13] has tracked CLSC performance according to the three types of government subsidy to increase return rates of used products from customers on the CLSC channel. They pointed out that government support can contribute significantly to environmental effects as well as economic effects.

Chen and Chang [14] deal with the strategic issue of closed-loop supply chains with remanufacturing by developing analytical models under cooperative and competitive settings. The primary goal behind the analytic formulation is 
to investigate under what conditions an original equipment manufacturer (OEM) may take a cooperative approach by participating in remanufacturing. In contrast, the OEM may take a competitive approach by letting the third-party firm remanufacture the returned cores and remarket in the secondary market that competes with the new product.

The above studies considered only general contract design, such as the revenue sharing of the manufacturer, in the coordination among the collection partners $[5,10,15]$. Numerous formats of the contract between the manufacturer and retailer have been studied, such as buy-back, quantity-flexibility, revenue-sharing, price-discount, salesrebate, and quantity discount [16-21]. However, when a manufacturer contracts with collector partners, for example, a retailer or a recycler, it has no information about collection intensity and collection cost. Therefore, it is a challenging problem for the manufacturer to design a proper contract mechanism under asymmetric partner information to maximize profits and ensure a sufficient collection rate. $\mathrm{Li}$ et al. [22] studied an incentive contract model in which a manufacturer assigns the used product collection to a company using only imperfect information on the company's collection costs under the extended producer responsibility (EPR) law. The contract design of the manufacturer incorporates the level of investment by its partner and the collection rate of that partner. Changes in contract design parameters in accordance with changes in the level of EPR law and remanufacturing cost were analyzed.

We propose three investment strategies of the manufacturer regarding two collection partners for an example of an ink cartridge: (1) the manufacturer shares some portion of its revenue with both partners, (2) the manufacturer shares some revenue with the retailer while paying a direct subsidy per unit returned cartridge to the recycler based on the number of used cartridges collected, and (3) a combination of (1) and (2).

The decisions about such strategic alternatives influence the volume of used products collected from customers, which in turn influences the profits of the partners and the revenue of the entire supply chain. Ultimately, the quantity of used products collected is an important factor linking cause and result variables in CLSC research. A critical assumption of most studies, however, is that the rate at which customers return used products is proportional to the size of the revenue shared by the manufacturer with collectors in collecting used products, regardless of customer willingness to respond to recycling rewards (cashback) offered by collectors. For example, where the retailer collects used products from its customers who directly visit the retailer, the rewards for the collection offered by the retailer to its customers, as well as the distance between the customers and the retailer, can be critical factors determining whether the customers will return the used products. The customers' tendency to favor cost savings by reuse can also affect collection activities. This study reflects not only the rewards for returning products provided to customers by the collection partner but also customer willingness, including their tendencies and their distance to the collector.

\section{System Dynamics Model}

3.1. Causal Relationships. A causal loop diagram (CLD) depicts the major variables linked together in a feedback cycle. In a CLD system, variables are linked by arrows that show interdependencies and feedback processes between variables, and the polarity markers near the arrows depict the effect of influence: positive for a direct effect and negative for an inverse influence [23].

Figure 1 depicts the causal loop diagram (CLD) of the CLSC model with a single recycler company and a retailer considered here. The goal of the model is to construct scenarios of various investment strategies used by the manufacturer with the collection partners, i.e., the retailer and the recycling company, and analyze the corresponding changes in the revenues of the manufacturer. Figure 1 also indicates the causal relationships in the manufacturer's strategy of sharing revenue with the retailer and the recycler. First, the manufacturer shares a part of its profit to encourage the retailer to collect used cartridges from customers. The retailer, in turn, uses the amount shared by the manufacturer to provide return rewards to customers. Consequently, the retailer's activity benefits the manufacturer by bringing in profits from selling more new products and providing used cartridges for the remanufacturing process, thereby reducing manufacturing costs.

By contrast, the recycler uses the shared revenue to visit customers who find it bothersome to return cartridges. Consequently, the activities of the recycler only impact the manufacturing cost since its collection activity does not generate sales.

The revenue shared by the manufacturer with each partner is limited; if the manufacturer shares a greater portion with the retailer, the recycler will receive less, and vice versa.

Under these scenarios, if the manufacturer pays more to the recycler, the manufacturing costs are reduced more because the recycler can visit more customers, which in turn brings in more used cartridges. This, however, will reduce the amount shared with the retailer, which reduces the number of rewards that the retailer can provide to customers. Thus, the number of cartridges returned to the retailer will decline, along with the volume of new purchases, which will ultimately reduce new cartridge sales and the collection of used cartridges. There is a danger that the manufacturer's profit will decline if the sharing amount disproportionately favors one partner over the other. It is, therefore, important for the manufacturer to determine the appropriate ratio of amounts to be shared with the retailer and recycler.

3.2. Simulation Model Description. The simulation method is used to capture the decision-making process of the manufacturer, retailer, and recycler in the CLSC model for used ink cartridges. Table 1 lists the Nomenclature used in the simulation model.

A system dynamics (SD) model using Vensim Pro 5.9e software was built to perform the simulation. Figure 2 


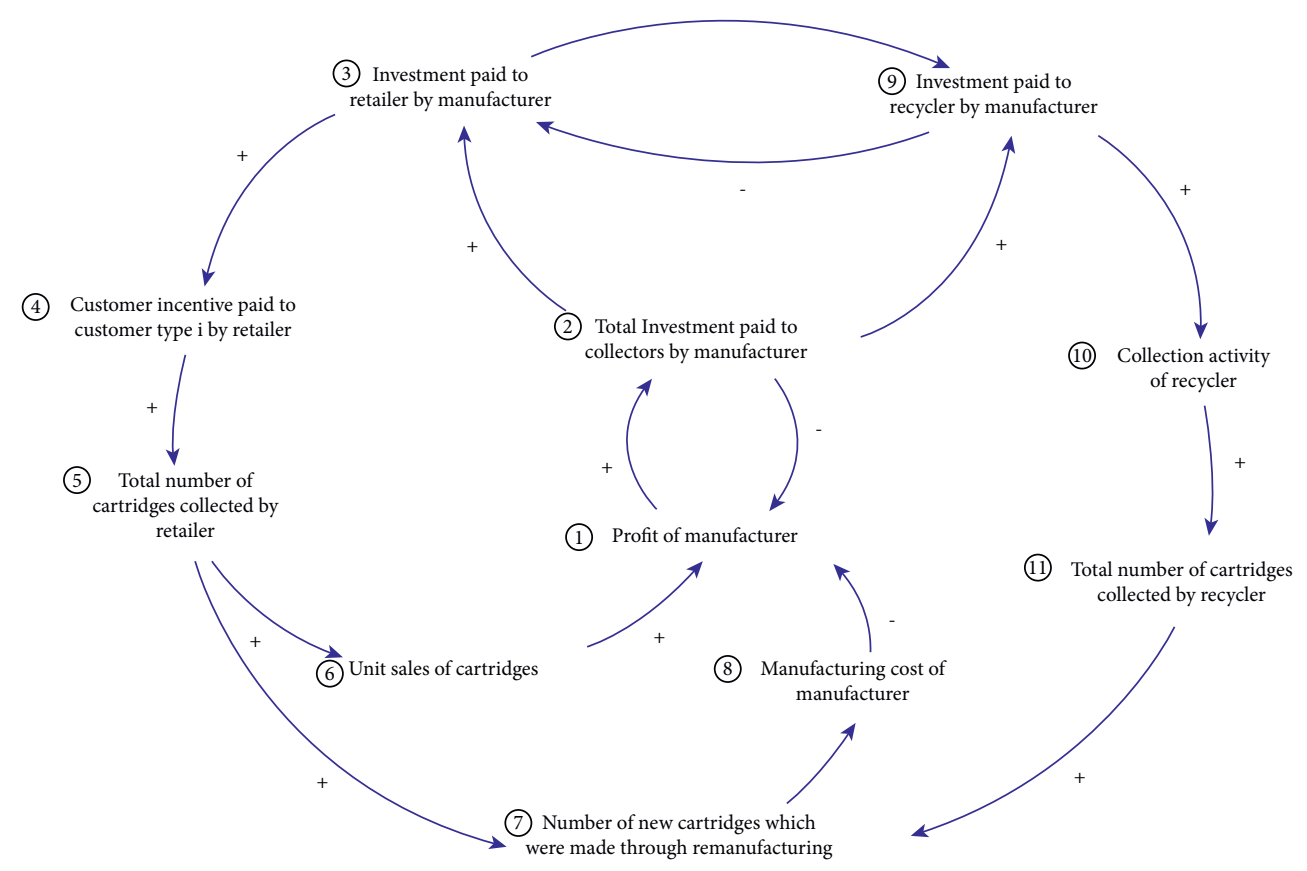

\begin{tabular}{|l|l|c|l|}
\hline \multicolumn{2}{|c|}{ Reinforcing Loop } & \multicolumn{2}{c|}{ Balance Loop } \\
\hline R1 & (1) $\rightarrow$ (2) $\rightarrow$ (3) $\rightarrow$ (4) $\rightarrow$ (5) $\rightarrow$ (6) $\rightarrow$ (1) & B1 & (1) $\rightarrow$ (2) $\rightarrow$ (9) $\rightarrow$ (3) $\rightarrow$ (4) $\rightarrow$ (5) $\rightarrow$ (7) $\rightarrow$ (8) $\rightarrow$ (1) \\
\hline R2 & (1) $\rightarrow$ (2) $\rightarrow$ (3) $\rightarrow$ (4) $\rightarrow$ (5) $\rightarrow$ (7) $\rightarrow$ (8) $\rightarrow$ (1) & B2 & (1) $\rightarrow$ (2) $\rightarrow$ (9) $\rightarrow$ (3) $\rightarrow$ (4) $\rightarrow$ (5) $\rightarrow$ (6) $\rightarrow$ (1) \\
\hline R3 & (1) $\rightarrow$ (2) $\rightarrow$ (9) $\rightarrow$ (10) $\rightarrow$ (11) $\rightarrow$ (7) $\rightarrow$ (8) $\rightarrow$ (1) & B3 & (1) $\rightarrow$ (2) $\rightarrow$ (3) $\rightarrow$ (9) $\rightarrow$ (10) $\rightarrow$ (11) $\rightarrow$ (7) $\rightarrow$ (8) $\rightarrow$ (1) \\
\hline & & B4 & (1) $\rightarrow$ (2) $\rightarrow$ (1) \\
\hline
\end{tabular}

Figure 1: Causal loop diagram of the CLSC in this study.

presents the elements of the system dynamics model. To capture the value of the manufacturer and the two partners, we describe the decision-making processes of all participants in the SD.

3.2.1. Customer Types. For the ink cartridge example, we consider two types of customers with used ink cartridges. The first type includes those customers who prefer to refill the used cartridges because refilling is less expensive than buying new cartridges; these customers do not discard or return the used cartridges. Cooperation between the manufacturer and retailer is crucial in inducing these customers to return their used products; it is assumed that these customers would participate in the return cycle if the cost associated with returning the used cartridges and purchasing new ones was no different from that of refilling the used cartridges. Thus, the retailer would be able to change the customer's decision by providing sufficient rewards to return the used cartridges and purchase new ones.

The second type includes those customers who prefer to discard used cartridges as they find it bothersome to visit retailers to return used products. This group does not consider the return activity important. As they dislike visiting the retailer for this purpose, they will discard the cartridges when the ink runs out and purchase new ones via other channels, such as online markets.

Such customer behavior is observed more often among customers at a greater distance from the retailer, potentially implying that customers located nearer to the retailer would find the offered rewards more attractive and respond by returning the cartridges. The manufacturer would provide sufficient financial support to the retailer to offer collection rewards to customers by sharing more of its own revenue. In addition to addressing this customer segment, the manufacturer may consider employing a recycler to visit customers directly to collect used products.

Figure 3 shows the changes in customer types prior to and after the manufacturer, retailer, and recycler implement strategies to collect used cartridges. The left side shows the initial state of the customer grouping before the retailer and recycler collect the empty cartridges. At this point, the customers are grouped into those who prefer to refill and those who prefer to discard the used cartridges.

The right side shows the shift to four customer types after the retailer and the recycler introduce activities that encourage used ink cartridge returns. The customers who initially preferred refilling the used cartridges are split 
TABLE 1: Nomenclature.

\begin{tabular}{|c|c|c|}
\hline \multicolumn{3}{|c|}{ Index } \\
\hline$t$ & \multicolumn{2}{|l|}{ Index of time period $\{1, \ldots, T\}$} \\
\hline$M$ & \multicolumn{2}{|l|}{ Manufacturer } \\
\hline$R$ & \multicolumn{2}{|l|}{ Retailer } \\
\hline $3 \mathrm{PL}$ & \multirow{2}{*}{\multicolumn{2}{|c|}{$\begin{array}{c}\text { Recycler }=\text { Third-party logistics company } \\
\text { Customer type }(1=\text { Customer who wants to discard the used cartridge, } 2=\text { Customer who wants to refill the used } \\
\text { cartridge })\end{array}$}} \\
\hline$i$ & & \\
\hline$j$ & \multirow{2}{*}{\multicolumn{2}{|c|}{$\begin{array}{l}\text { Collector type }(1=\text { Retailer, } 2=\text { Recycler }) \\
\text { Customer group based on distance from the retailer }(1=\text { first closest customer group, } \ldots, 5=\text { fifth closest customer } \\
\text { group } \in(1,2,3,4,5)\end{array}$}} \\
\hline$k$ & & \\
\hline$\tau$ & \multicolumn{2}{|l|}{ Scaling parameter } \\
\hline Terms & Description & Measure \\
\hline $\mathrm{RP}$ & Retail price & \$/unit \\
\hline RFP & ReFilling price & \$/unit \\
\hline WP & Wholesale price & \$/unit \\
\hline RCF & ReCycling & Fee \$/unit \\
\hline MC & Manufacturing cost & \$/unit \\
\hline PMC & ReManufacturing cost & \$/unit \\
\hline $\mathrm{PR}_{i \in\{1\}, k, t}$ & Perceived rewards of customer in period $t$ & \$/unit \\
\hline$D_{t}$ & Demand of new customers purchasing cartridge in period $t$ & Person/month \\
\hline $\mathrm{NC}_{i t}$ & Number of Customer type $i$ in period $t$ & Person/month \\
\hline $\mathrm{WC}_{i \in\{1\}, k, t}$ & Willingness of Customer group $k$ of customer type 1 in period $t$ & $\% /$ month \\
\hline $\mathrm{WC}_{i \in\{2\}, t}$ & Willingness of Customer type 2 in period $t$ & $\% /$ month \\
\hline QREM & Quantity of new cartridges REManufactured in period $t$ & units/month \\
\hline $\mathrm{SP}^{j}$ & Sharing Portion paid to collector $j$ by manufacturer & $\% /$ month \\
\hline $\mathrm{TCR}_{t}^{R}$ & Total number of Cartridges collected by Retailer in period $t$ & units/month \\
\hline $\mathrm{RE}_{t}^{R}$ & Return Rewards paid to the customer by the retailer in period $t$ & \$/month \\
\hline $\operatorname{REmax}_{t}^{R}$ & MAXimum return REwards paid to customer type $i$ by retailer & \$/month \\
\hline $\mathrm{BRR}^{i}$ & Basic Rewards Rate set by retailer & $\%$ \\
\hline $\mathrm{BRF}^{3 \mathrm{PL}}$ & Basic Recycling fee set by Recycler & $\$$ \\
\hline $\mathrm{CRP}_{t}^{R}$ & Change rate of Retailer's Profit in period $t$ & $\% /$ month \\
\hline $\mathrm{WF}_{k}$ & Weight factor based on the distance between the retailer and customer group $k$ & \\
\hline $\mathrm{REV}_{t}$ & Total REVenue in period $t$ & \$/month \\
\hline $\operatorname{COST}_{t}$ & Total COST in period $t$ & \$/month \\
\hline $\mathrm{TS}_{t}^{M}$ & Total amount shared by the manufacturer with the retailer and recycler in period $t$ & \$/month \\
\hline PROFIT $_{t}$ & Total PROFIT in period $t$ & \$/month \\
\hline
\end{tabular}

between those who maintain their decision to refill and those who do not. Thus, some customers who prefer to refill decide to return their used cartridges to the retailer and buy new ones; their decision to refill or return will be dependent on the difference between the refill cost and the size of the rewards offered by the retailer.

Simultaneously, the customers who previously preferred to discard used products are newly segmented into two groups: those who return the used products via the recycler and those who still discard their used cartridges.

Customers who are physically closer to the retailer will respond more readily to the strategy by encouraging ink cartridge returns; that is, proximity to the retailer influences customers' perceptions of the rewards scale. To apply this concept to the relative perception of customers, we classified customers into five groups depending on their proximity to the retailer, from the first closest to the fifth closest. The perceived rewards scale is considered lower for customers with a greater physical distance from their retailer. Thus, the perceived rewards scale is calculated by multiplying the actual amount of rewards provided by the retailer by the weight factor of the distance between the retailer and customers. Among those who previously preferred disposal, some who are not responsive to the return rewards offered by the retailer because it is bothersome to visit the retailer directly will choose to return their cartridges if the recycler visits their location. We assume the recycler only pays them a basic return fee that is lower than the retailer reward. Finally, the remaining customers who are not attracted by the basic return fee offered by the recycler will maintain their initial choice to discard the used cartridges.

3.2.2. Manufacturer Profit. Manufacturer profit occurs when new products are sold via FSCs. Customers who purchase new products through the FSC are classified into new customers and previous customers who return their used products to the retailer. The total revenue of the manufacturer in the previous period can be defined as

$$
\operatorname{REV}_{t}^{M}=\left[\left(D_{t}+\mathrm{TCR}_{t}^{R}\right) \times \mathrm{WP}\right], \quad t=1,2, \ldots, T .
$$

In general, the manufacturing cost of new products is considered greater than the cost of remanufacturing used products. Savaskan et al. [2] indicated that the savings of 

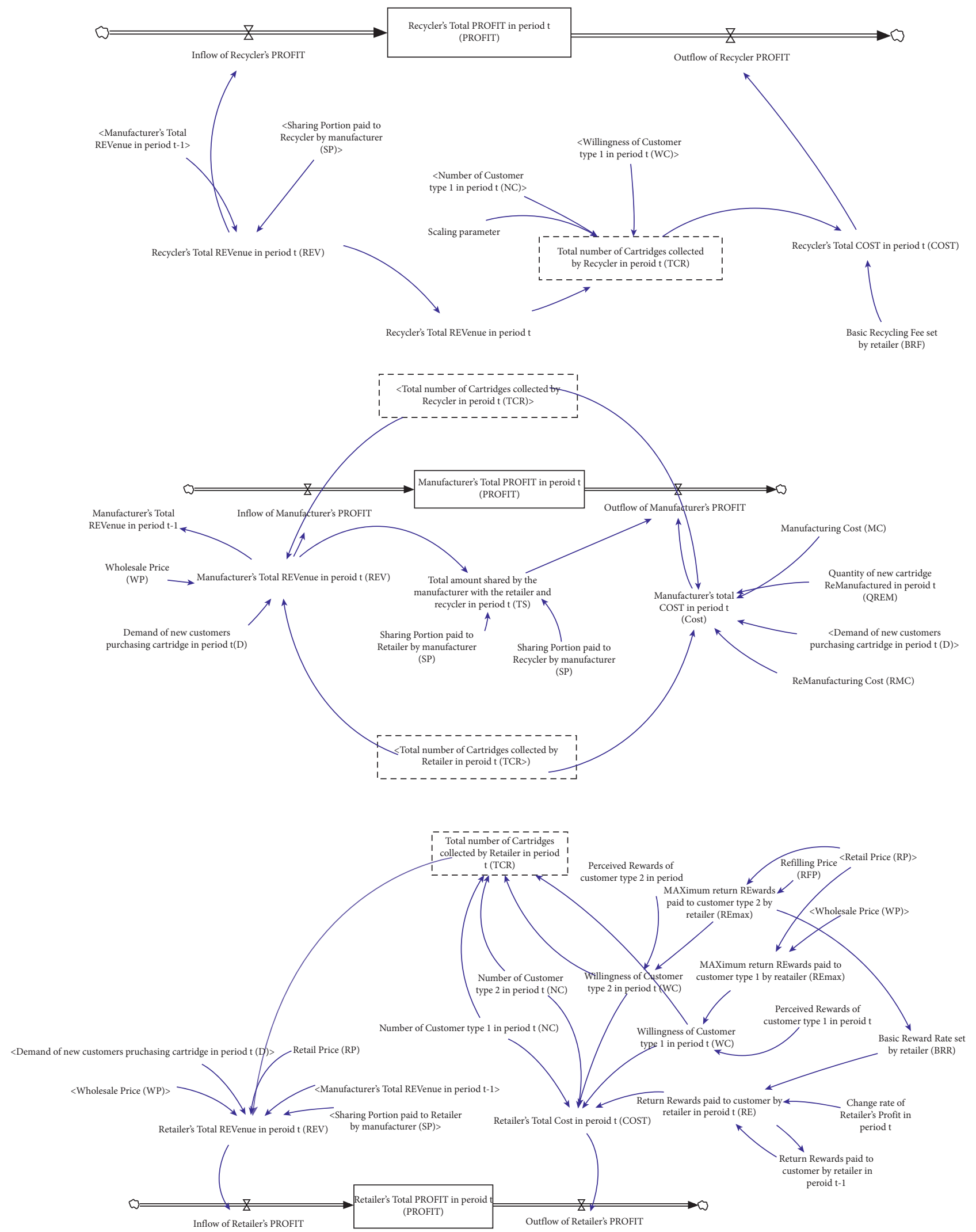

FIGURE 2: CLSC with a single manufacturer, single retailer, and single recycler. 


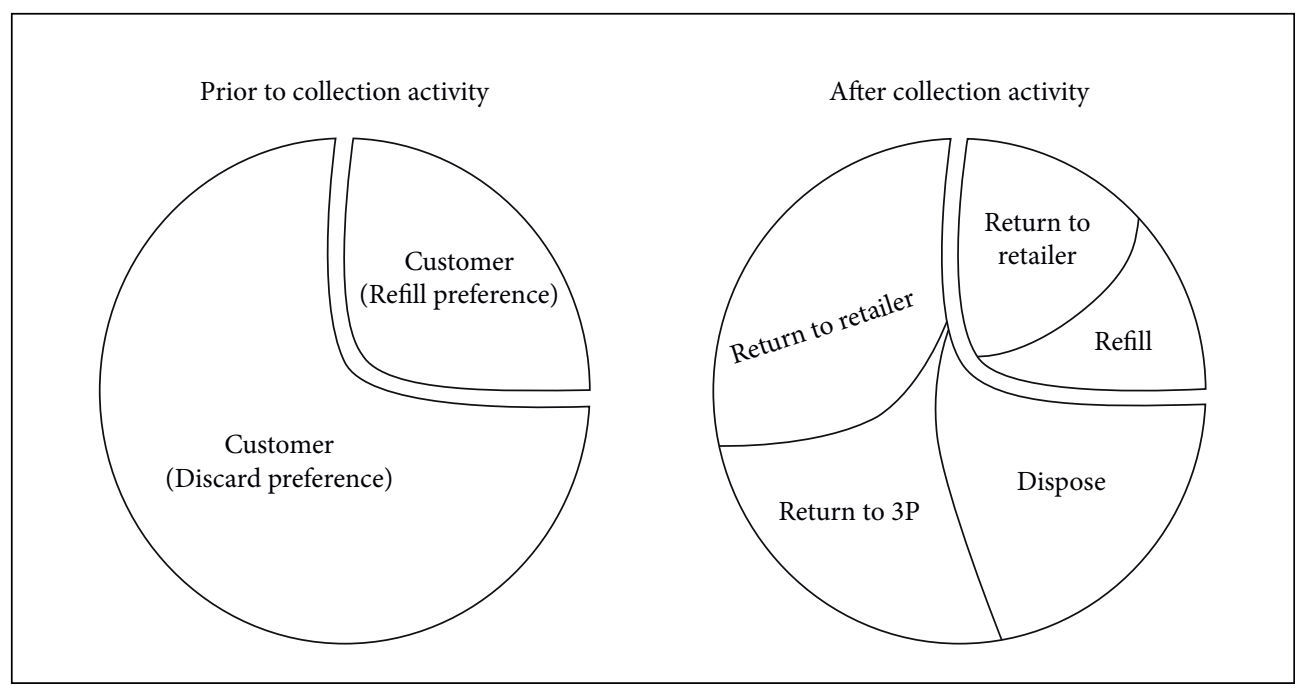

FIgURE 3: Changes in customer types prior to and after the collection activity.

materials and the assembly of subsystems for a new product are greater than the additional costs of disassembly, inspection for reusability, and the cost of remanufacturing. Consequently, the manufacturing cost of new ink cartridges will decrease as the number of cartridges produced by the remanufacturing process increases. The equation is designed to apply the remanufacturing cost if the proportion of remanufactured cartridges is small and use the manufacturing cost for the remaining product volume. Therefore, the total manufacturing cost of the manufacturer in each period can be defined according to

$$
\operatorname{COST}_{t}^{M}=\left\{\begin{array}{c}
\left(D_{t}+\mathrm{TCR}_{t}^{R}\right) \geq \mathrm{QREM}_{t}^{M},\left[\left(D_{t}+\mathrm{TCR}_{t}^{R}\right)-\mathrm{QREM}_{t}^{M}\right] \times \mathrm{MC}+\left(\mathrm{QREM}_{t}^{M} \times \mathrm{RMC}\right) \\
\left(D_{t}+\mathrm{TCR}_{t}^{R}\right)<\mathrm{QREM}_{t}^{M},\left[\left(D_{t}+\mathrm{TCR}_{t}^{R}\right) \times \mathrm{RMC}\right]
\end{array}\right\}, \quad t=1,2, \ldots, T
$$

In addition, the manufacturer shares some revenue to allow the retailer and recycler to collect the used cartridges more proactively. This study seeks to analyze the changes to the manufacturer's profit depending on the amount of revenue shared with each partner by each sharing method. Equation (3) indicates the total amount of revenue sharing by the manufacturer with the retailer and recycler in each period. Thus, the manufacturer's profit during the total simulation time is calculated from the difference between the total revenue and the sum of the cost of manufacturing new cartridges and the amount of revenue shared with each of the retailer and the recycler, as shown in

$$
\begin{aligned}
\mathrm{TS}_{t}^{M} & =\sum_{j} \mathrm{REV}_{t}^{M} \times \mathrm{SP}^{j}, \quad t=1,2, \ldots, T, j=1,2, \\
\mathrm{PROFIT}^{M} & =\int_{t=0}^{T} \mathrm{REV}_{t}^{M}-\mathrm{COST}_{t}^{M}-\mathrm{TS}_{t}^{M} \mathrm{~d} t .
\end{aligned}
$$

3.2.3. Retailer Profit. Because customers who return their used cartridges to the retailer will buy new ones from the retailer, a larger volume of used ink cartridges returned to the retailer will increase new cartridge sales. Although the retailer seeks to collect used ink cartridges to gain increase sharing by the manufacturer, more significantly, the retailer has more opportunities to sell new products when customers return used cartridges. The rewards offered by the retailer to the customers originate from the sales profit in the previous period and the revenue shared by the manufacturer.

The retailer provides distinct rewards to customers who prefer disposal and those who prefer to refill their used cartridges. Because the former group will return more cartridges when the rewards scale is larger, it is assumed that 


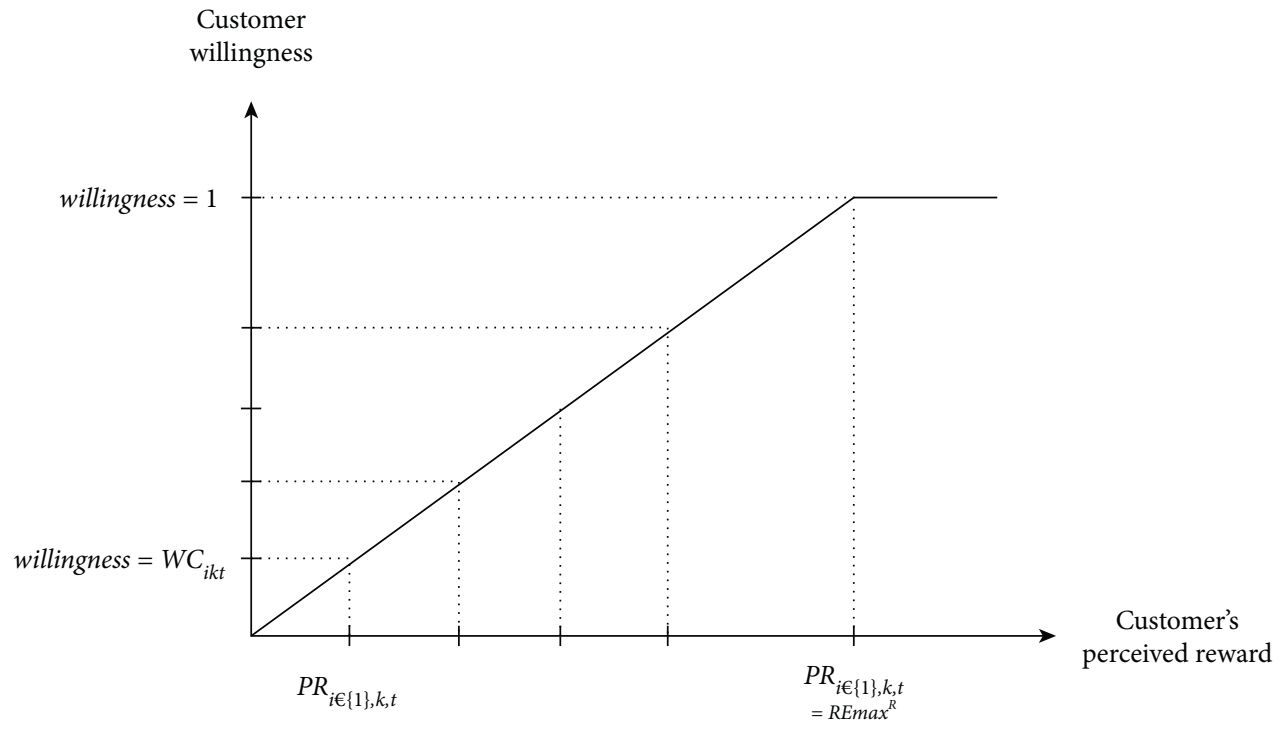

FIGURE 4: Linear function of the willingness to return according to the change in the customer's perceived rewards.

the retailer will set a minimum reward for these customers and adjust the magnitude of the reward in the following periods depending on the profit changes in the previous period. Equations (5) through (7) address the rewards offered to customers preferring disposal.

$$
\begin{aligned}
\operatorname{REmax}_{i}^{R} & = \begin{cases}\mathrm{RP}-\mathrm{WP}, & i=1, \\
\mathrm{RP}-\mathrm{RFP}, & i=2,\end{cases} \\
\mathrm{RE}_{i t}^{R} & =\left\{\max \left[\mathrm{BRR}^{R} \times \mathrm{REmax}_{i}^{R}, \mathrm{RE}_{i t-1}^{R}+\left[\left(1-\mathrm{BRR}^{R}\right) \times \mathrm{REmax}_{i}^{R} \times \mathrm{CRP}_{t}^{R}\right]\right]\right\}, \quad i=1,2 ; t=1,2, \ldots, T, \\
\mathrm{RE}_{i, t=0}^{R} & =\mathrm{BRR}^{R} \times \mathrm{REmax}_{i}^{R}, \quad i=1,2 .
\end{aligned}
$$

Whether disposal-leaning customers will alter their decision is determined by the customer's perception of the rewards provided by the retailer, which is dependent on the customer's geographic distance from the retailer. We defined this concept as perceived perception and assumed that the customer's willingness to return rather than discard is linearly proportional to the size of the perceived rewards (see equation (8)), as shown in Figure 4 [15].

$$
\mathrm{WC}_{i \in\{1\}, k, t}= \begin{cases}\frac{\mathrm{PR}_{i \in\{1\}, k, t}}{\operatorname{REmax}_{i \in\{1\}}^{R},} & 0<\mathrm{PR}_{i \in\{1\}, k, t}<\operatorname{REmax}_{i \in\{1\}}^{R}, \\ 1, & \mathrm{PR}_{i \in\{1\}, k, t}>\operatorname{REmax} \operatorname{ma}_{i \in\{1\}}^{R}, \quad k=1,2, \ldots, 5 ; t=1,2, \ldots, T .\end{cases}
$$

Furthermore, we define the probability of collecting cartridges from customers who prefer to refill them as customer willingness to return rather than refill. As shown in equation (9), the probability to collect used cartridges is determined by the difference between the cost to refill and the cost to purchase new products at the discount price offered for returning cartridges. The customer's willingness to return rather than refill increases when the discount price of the new product is closer to the cost of the refill; if there is no difference between the former and the latter costs, we assume that all refill-preferring customers will choose to return their used ink cartridges [10].

$$
\mathrm{WC}_{i \in\{2\}, t}=\frac{\operatorname{RE}_{i \in\{2\}, t}^{R}}{\operatorname{REmax}_{i \in\{2\}}^{R}}, \quad t=1,2, \ldots, T
$$


Finally, equation (10) indicates the number of customers who prefer to discard rather than return the used ink cartridges and the volume of collected cartridges from refillpreferring customers.

$$
\mathrm{TCR}_{t}^{R}=\sum_{k} \mathrm{NC}_{i \in\{1\}, t} \times \mathrm{WC}_{i \in\{1\}, k, t}+\mathrm{NC}_{i \in\{2\}, t} \times \mathrm{WC}_{i \in\{2\}, t}, \quad t=1,2, \ldots, T .
$$

New product sales are generated from new customers and from customers who return used cartridges and buy new ones. Equation (11) shows that the retailer's revenue comprises sales profits from new cartridges and the amount shared by the manufacturer to encourage customers to return used products. The costs paid to the customer by the retailer, as shown in equation (12), are determined by the size of the rewards for each customer. Consequently, the profit of the retailer can be defined according to equation (13):

$$
\begin{aligned}
\mathrm{REV}_{t}^{R} & =\left(D_{t}+\mathrm{TCR}_{t}^{R}\right) \times(\mathrm{RP}-\mathrm{WP})+\mathrm{REV}_{t-1}^{M} \times \mathrm{SP}^{R}, \quad t=1,2, \ldots, T, \\
\mathrm{COST}_{t}^{R} & =\left(\sum_{k} \mathrm{NC}_{i \in\{1\}, t} \times \mathrm{WC}_{i \in\{1\}, k, t}\right) \times R E_{i \in\{1\}, t}^{R}+\left(\mathrm{NC}_{i \in\{2\}, t} \times \mathrm{WC}_{i \in\{2\}, t}\right) \times \mathrm{RE}_{i \in\{2\}, t}^{R}, \quad t=1,2, \ldots, T, \\
\operatorname{PROFIT}^{R} & =\int \mathrm{REV}_{t}^{R}-\mathrm{COST}_{t}^{R} \mathrm{~d} t .
\end{aligned}
$$

3.2.4. Recycler Profit. The recycler collects used products by visiting customers who prefer disposal. The current study assumes that the volume of cartridges collected by the recycler is proportional to its ability to visit customers within a given period, which in turn is determined by the portion of the profit shared by the manufacturer [2] (see equation (15)).
The recycler's profits are determined by the profits shared by the manufacturer minus the basic return fee required to visit customers and collect used cartridges, as indicated by

$$
\begin{aligned}
\mathrm{REV}_{t}^{3 \mathrm{PL}} & =\mathrm{REV}_{t-1}^{M} \times \mathrm{SP}^{3 \mathrm{PL}}, \quad t=1,2, \ldots, T, \\
\mathrm{TCR}_{t}^{3 \mathrm{PL}} & =\left[\mathrm{NC}_{i \in\{1\}, t}-\left(\sum_{k} \mathrm{NC}_{i \in\{1\}, t} \times \mathrm{WC}_{i \in\{1\}, k, t}\right)\right] \times \sqrt{\frac{\mathrm{REV}_{t}^{3 \mathrm{PL}}}{\tau}, t=1,2, \ldots, T,} \\
\mathrm{COST}_{t}^{3 \mathrm{PL}} & =\mathrm{BRF}_{i=1}^{3 \mathrm{PL}} \times \mathrm{TCR}_{t}^{3 \mathrm{PL}}, \quad t=1,2, \ldots, T, \\
\mathrm{PROFIT}^{3 \mathrm{PL}} & =\int_{t=0}^{T} \mathrm{REV}_{t}^{3 \mathrm{PL}}-\mathrm{COST}_{t}^{3 \mathrm{PL}} \mathrm{d} t .
\end{aligned}
$$

\section{Simulation Experiment Results}

We analyzed how much an investment would maximize profits when the manufacturer invests a percentage in two channels with different return objectives. When making decisions about the size of the investment, the manufacturer considers the following relationship. If the manufacturer allocates a large share of the profits to the retailer, the return volume from customers who prefer refilling will be large, and chances for the manufacturer to sell new cartridges will increase. However, sharing more profits with the retailer reduces the rate of investment in the recycler and makes it difficult to collect more cartridges from customers who prefer disposal. The reduced recovery by the recycler also reduces the manufacturer's opportunity to reduce production costs by remanufacturing the returned cartridges during a new cartridge production process. Therefore, manufacturers should determine the appropriate ratio of investment to be paid to the two channels by analyzing the trade-offs between the opportunity to sell new products by investing in the retailer and the reduction in production costs created by investing in the recycler.

Equation (18) shows the manufacturer's profitable relationship for the simulation experiment. Here, $s$ represents 
the difference between the wholesale price and the manufacturing cost of a new cartridge, and $k$ is the difference between the cost of manufacturing and remanufacturing. That is, the value of $s$ reflects the size of the manufacturer's profit margin when the retailer sells a new cartridge to a customer who prefers to refill. The value of $k$ reflects the size of the cost-saving effect of using a cartridge collected by the recycler to produce a new cartridge. As both benefits can vary with changes in $s$ and $k$, we set the ranges of $s$ and $k$ and performed a sensitivity analysis to track the differences in the ratio of investments in both channels according to these changes. The interim values of $s$ and $k(s=0.65 ; k=0.6)$ were used as the initial values for the experiment.

$$
\left\{\begin{aligned}
\mathrm{MC} & =s . \mathrm{WP}, & & 0.5 \leq s \leq 0.8, \\
\mathrm{RMC} & =k . \mathrm{MC}, & & 0.4 \leq s \leq 0.8 .
\end{aligned}\right.
$$

4.1. Manufacturer's Revenue-Sharing Investment Strategy. Figure 5 describes the procedure in which the manufacturer applies the revenue-sharing investment (RSI) strategy at time $t$. Based on the sales and recovery activities of the retailer and recycler, respectively, over the period $t-1$ (previous period), the manufacturer calculates its net profit at the beginning of period $t$. Some portion of the net profit is then set as an investment budget to support the return of used cartridges by retailers and recyclers over the period $t$. The manufacturer determines the percentage of the investment budget to invest in each retailer and recycler.

Figure 6 and Table 1 show the manufacturer's profit margin, cost savings, and net profits by increasing and decreasing the investment shares of the retailer and recycler by $5 \%$ with $s=0.65$ and $k=0.6$. The results of the experiment show that there is a greater effect on profit sharing at the proper level than investing in either channel. This result proves that new cartridge sales due to investments in retailers and the savings in production costs from investments in recyclers have a trade-off relationship.

As shown in Table 2, when $s=0.65$ and $k=0.6$, the manufacturer generates the highest profits when investing equal portions of its profits in the retailer and recycler. We further analyzed the investment amount paid per unit returned based on the investment amounts paid to the retailer and the recycler using the optimal rate. This analysis was performed to investigate whether the size of the investment in both channels is excessive to the volume actually returned when the manufacturer applies the RSI strategy.

As stated above, the effect expected by the manufacturer in supporting the return channel with the retailer is that customers who preferred refilling visit the retailer to return used cartridges and buy new ones. Thus, the manufacturer's per unit profit from the recovery of a unit used cartridge by the retailer is the difference between the wholesale price and the manufacturing cost. When $s=0.65$, since the marginal investment per unit (WP-MC) is 0.35 , it is appropriate for the manufacturer to invest 0.31 per unit of recovery volume in the retailer. By contrast, the effect expected by the manufacturer from investing in the recycler's return activity is to increase the return rate of the recycler by providing customers who preferred to dispose of their used cartridges with the proper incentive.

Thus, the expected effect of the manufacturer is to reduce manufacturing costs by remanufacturing returned cartridges, which is expressed as WC-RMC. When $k=0.6$, the marginal manufacturing cost per unit cartridge is 0.29 (0.65-0.39). Since the manufacturer invests 0.34 in the recycler to return per unit in the RSI strategy, an overinvestment of 0.08 occurs. This excess investment occurs because the manufacturer paid part of its profits without understanding the level of the return rate against the investment in the recycler.

\subsection{Direct Subsidy Payment per Unit Returned Cartridge.} To prevent excess investment in the recycler when the RSI strategy is applied, a direct subsidy per unit returned cartridge (DSURC) strategy is proposed. This strategy consists of paying the recovery activity subsidy at the beginning of period $t$ in proportion to the return rate of the recycler during period $t-1$ before applying the RSI strategy.

Figure 7 shows the detailed procedure for implementing the DSURC strategy. Similar to the RSI strategy, the manufacturer allocates a portion of its net profit to both channels at a predetermined rate. However, in the total investment, the manufacturer first allocates the basic subsidy per unit for the amount collected by the recycler during period $t-1$. The manufacturer then determines the size of the investment to be paid to each retailer and recycler for the remaining investment. A major decision in this strategy is to determine how much the manufacturer allocates for the additional subsidy per unit to promote the activity during period $t$ in addition to the basic subsidy to the recycler. The total amount of additional grants per unit is also paid in proportion to the number of used cartridges collected by the recycler over period $t$, and the remaining amount is paid to the retailer as the investment during period $t$.

The results of the experiment using this strategy to maximize the manufacturer's profit are shown in Table 3. The net profit of the manufacturer is 12.9 , indicating better results than with the RSI strategy. In the analysis of the unit investment, the unit investment paid to the recycler is 0.22 , which is lower than the marginal cost of 0.26 . Thus, the DSURC strategy is effective in preventing excess investment. However, the DSURC strategy can negatively affect the return rate of the recycler because the reduction in unit investment will lower the incentive levels offered to customers who preferred disposal.

To monitor these phenomena, we examined the differences in the return rate of the recycler between the RSI strategy and the DSURC strategy. The recycler's return rate is approximately 7\% lower under the DSURC strategy than under the RSI strategy. Of course, this reduced share of the investment in the recycler compared with the RSI strategy increases the share of the investment in the retailer and the return rate of the retailer. However, as shown in Figure 1, because the number of customers that the recycler visits is larger than the number of customers who visit the retailer, the increase in the return rate from the retailer has a limited effect on maximizing the manufacturer's net profit. 


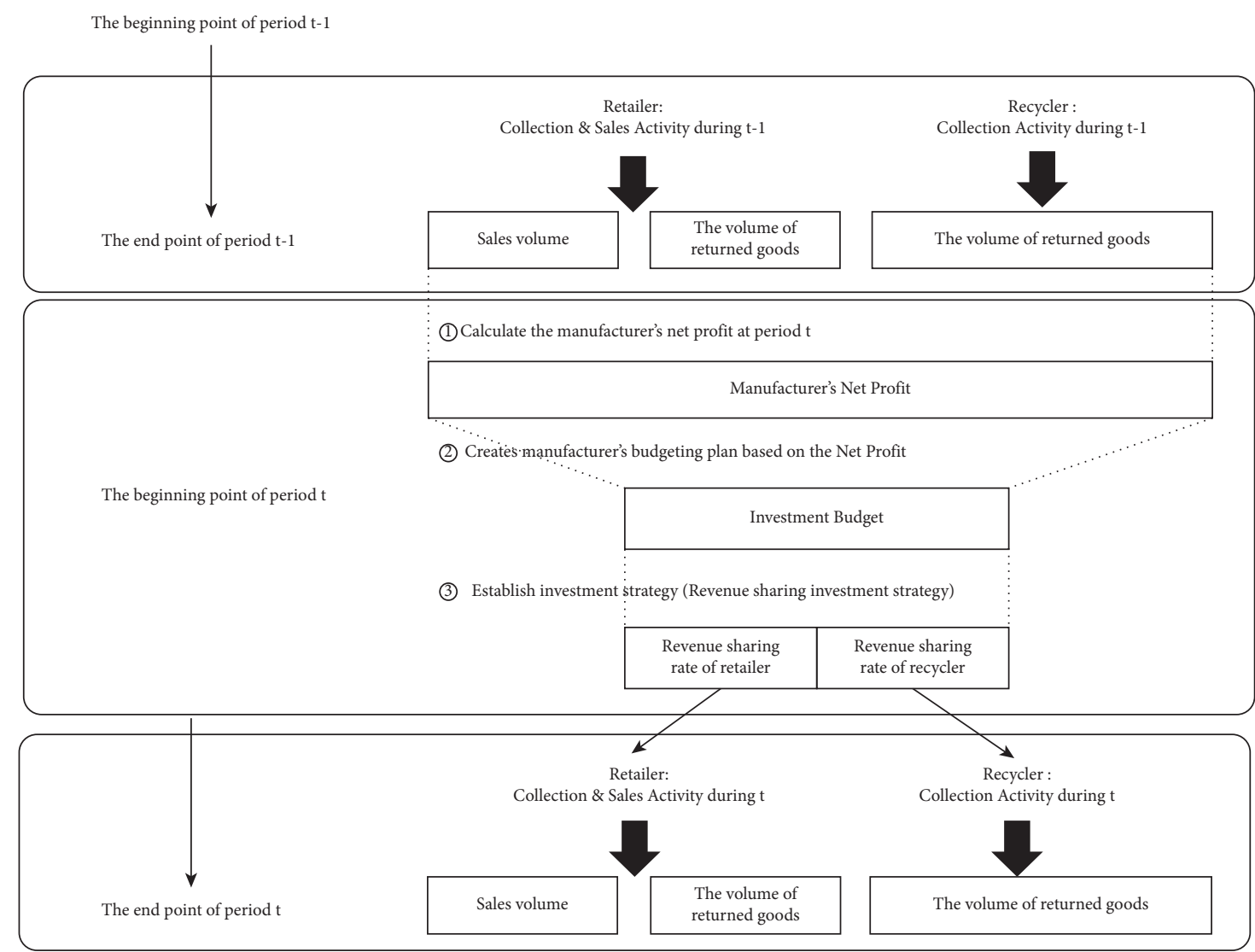

FIgURE 5: Linear function of the willingness to return according to the change in the customer's perceived rewards.

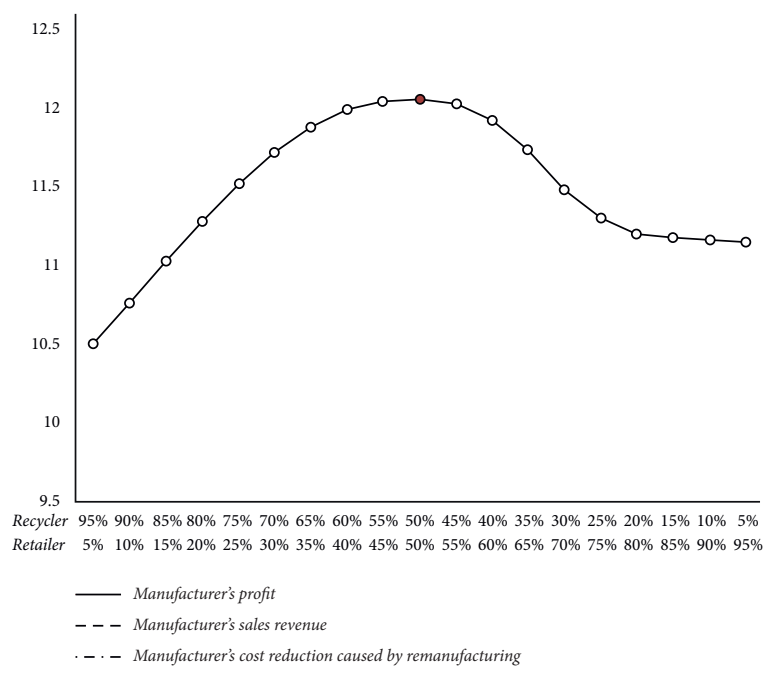

(a)

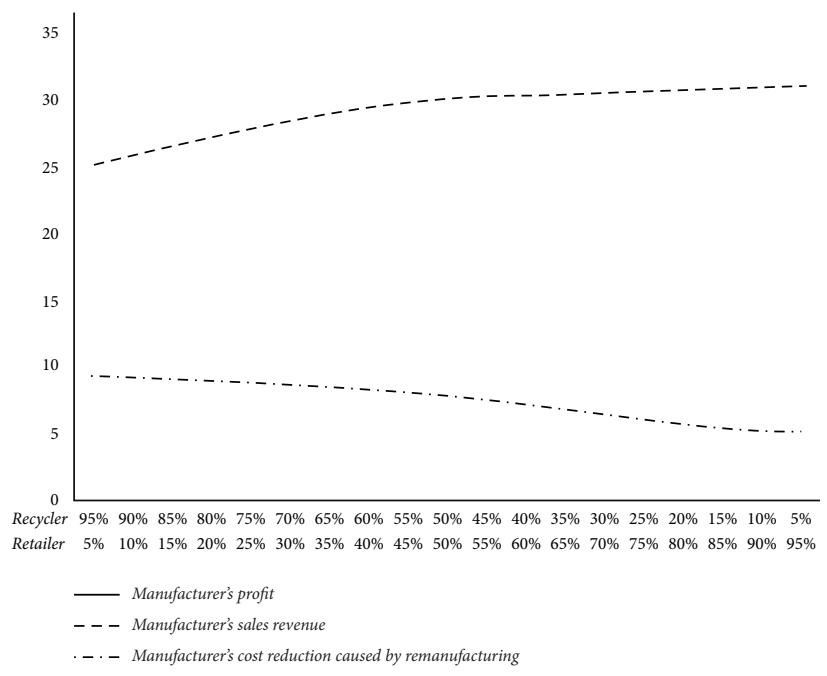

(b)

Figure 6: A graphical presentation of the results for the revenue-sharing strategy $(s=0.65, k=0.6)$.

4.3. Manufacturer's Hybrid Investment Strategy. Figure 8 shows the implementation procedures for the hybrid strategy to complement the weaknesses of the RSI and DSURC strategies. Similar to the DSURC strategy, the manufacturer pays the basic subsidy to the recycler based on the number of used cartridges collected during period $t-1$. For the remaining investments, as with the RSI strategy, the optimal sharing ratio for the two channels is determined to maximize the manufacturer's profits. This strategy avoids excessive investment by providing basic grants for the performance of the return activities the recycler has performed over the previous period. 
TABLE 2: Results for the revenue-sharing strategy $(s=0.65, k=0.6)$.

\begin{tabular}{|c|c|c|c|c|c|}
\hline \multicolumn{2}{|c|}{ Manufacturer's investment } & \multirow{2}{*}{$\begin{array}{l}\text { Manufacturer's } \\
\text { profit }\end{array}$} & \multirow{2}{*}{$\begin{array}{c}\text { Manufacturer's sales } \\
\text { revenue }\end{array}$} & \multirow{2}{*}{$\begin{array}{l}\text { The effect of manufacturing } \\
\text { cost reduction }\end{array}$} & \\
\hline Retailer (\%) & Recycler (\%) & & & & \\
\hline 5 & 95 & 10.51 & 25.08 & 9.34 & \\
\hline 10 & 90 & 10.76 & 25.73 & 9.22 & \\
\hline 15 & 85 & 11.04 & 26.48 & 9.12 & \\
\hline 20 & 80 & 11.28 & 27.18 & 9.01 & \\
\hline 25 & 75 & 11.52 & 27.88 & 8.88 & \\
\hline 30 & 70 & 11.72 & 28.51 & 8.73 & \\
\hline 35 & 65 & 11.88 & 29.04 & 8.54 & \\
\hline 40 & 60 & 11.99 & 29.49 & 8.34 & \\
\hline 45 & 55 & 12.04 & 29.83 & 8.12 & \\
\hline 50 & 50 & 12.06 & 30.10 & 7.88 & \\
\hline 55 & 45 & 12.03 & 30.28 & 7.63 & \\
\hline 60 & 40 & 11.92 & 30.30 & 7.35 & \\
\hline 65 & 35 & 11.73 & 30.43 & 6.99 & \\
\hline 70 & 30 & 11.48 & 30.58 & 6.55 & \\
\hline 75 & 25 & 11.30 & 30.67 & 6.11 & \\
\hline 80 & 20 & 11.20 & 30.76 & 5.76 & \\
\hline 85 & 15 & 11.18 & 30.89 & 5.50 & \\
\hline 90 & 10 & 11.17 & 30.99 & 5.30 & \\
\hline 95 & 5 & 11.15 & 31.10 & 5.16 & \\
\hline \multicolumn{6}{|c|}{ Detailed analysis of optimal investment in the revenue-sharing strategy } \\
\hline \multicolumn{2}{|c|}{$\begin{array}{l}\text { Total investment of } \\
\text { manufacturer }\end{array}$} & Manufacturer's profit & \multicolumn{2}{|c|}{$\begin{array}{l}\text { Proportion of customers } \\
\text { who return cartridges }\end{array}$} & $\begin{array}{c}\text { Manufacturer's } \\
\text { investment/ } \\
\text { returned cartridge } \\
\text { unit }\end{array}$ \\
\hline Recycler & Retailer & & Recycler & Retailer & Recycler Retailer \\
\hline $4.36(50 \%)$ & $4.36(50 \%)$ & 12.06 & $67.8 \%$ & $32.2 \%$ & 0.34 \\
\hline
\end{tabular}

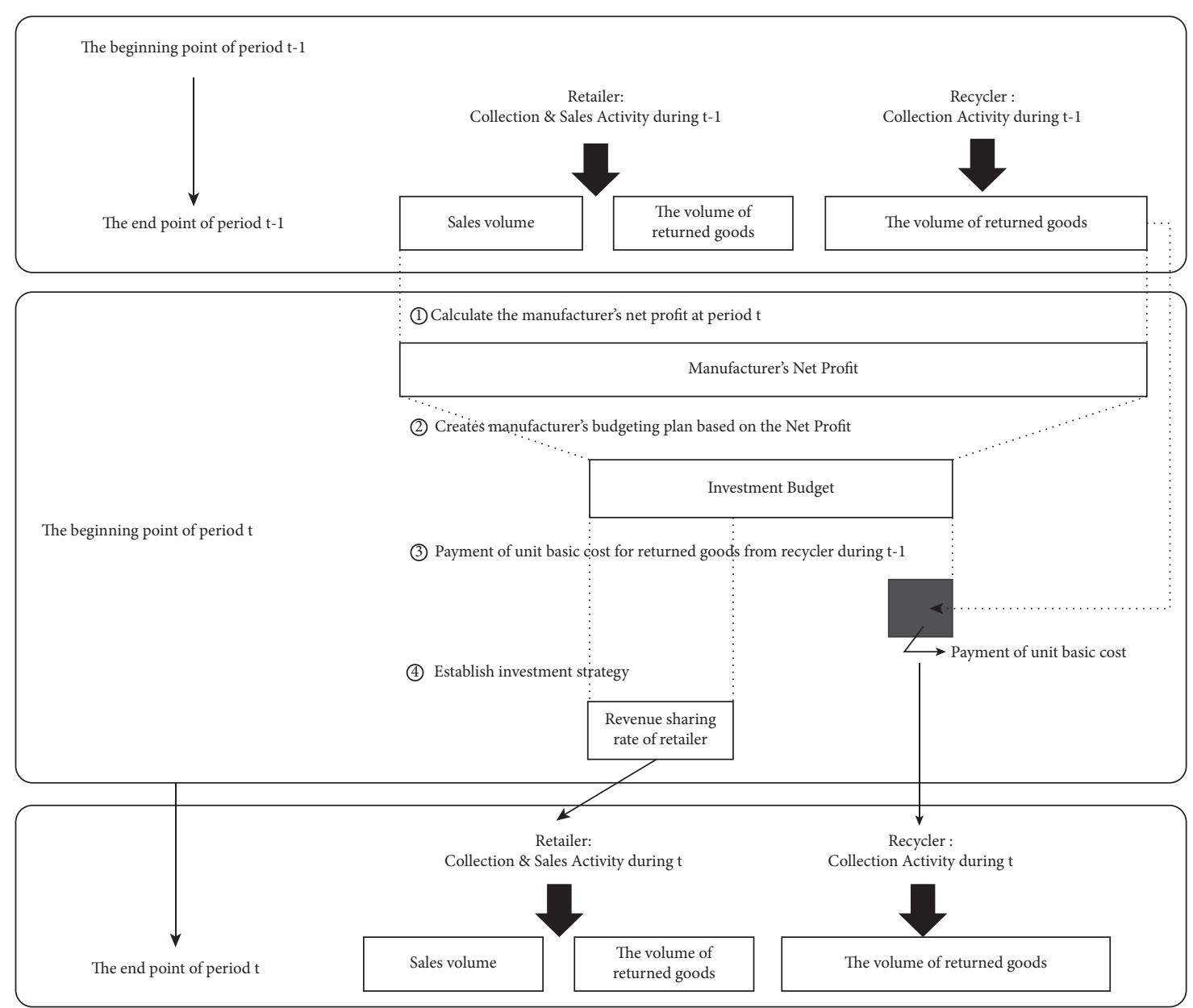

FIgURE 7: The procedure for direct payment per unit returned cartridge. 
TABLE 3: Results of the payment strategy per unit returned cartridge $(s=0.65, k=0.6)$.

\begin{tabular}{|c|c|c|c|c|c|}
\hline \multicolumn{2}{|c|}{ Manufacturer's investment } & \multirow{2}{*}{$\begin{array}{c}\text { Manufacturer's } \\
\text { profit }\end{array}$} & \multirow{2}{*}{$\begin{array}{l}\text { Manufacturer's } \\
\text { sales revenue }\end{array}$} & \multirow{2}{*}{$\begin{array}{c}\text { Total } \\
\text { investment }\end{array}$} & \multirow{2}{*}{$\begin{array}{l}\text { The effect of } \\
\text { manufacturing cost } \\
\text { reduction }\end{array}$} \\
\hline Retailer & Recycler & & & & \\
\hline \multirow{5}{*}{$\begin{array}{l}\text { Share of revenue from } \\
\text { manufacturing cost } \\
\text { reduction }+ \\
\text { Share of revenue from } \\
\text { new cartridge } \\
\text { sales }=(74 \%)\end{array}$} & $0.139 /$ return cartridge & 11.4 & 29.1 & 2.1 & 3.8 \\
\hline & $0.167 /$ unit returned cartridge & 12.4 & 30.3 & 3.8 & 6.4 \\
\hline & $0.222 /$ unit cartridge & 12.9 & 32.2 & 5.6 & \multirow[t]{2}{*}{8.5} \\
\hline & & & & & \\
\hline & $0.278 /$ return cartridge & 12.4 & 33.4 & 7.1 & 9.9 \\
\hline \multicolumn{6}{|c|}{ Detailed analysis of optimal investment in the payment strategy per unit returned cartridge } \\
\hline \multicolumn{2}{|c|}{ Total investment of manufacturer } & Manufacturer's & \multicolumn{2}{|c|}{$\begin{array}{l}\text { Proportion of customers who } \\
\text { return cartridges }\end{array}$} & $\begin{array}{l}\text { Manufacturer's investment/ } \\
\text { returned cartridge unit }\end{array}$ \\
\hline Recycler & Retailer & & Recycler & Retailer & Recycler \\
\hline $2.01(26 \%)$ & $5.81(74 \%)$ & 12.9 & $57.4 \%$ & $42.6 \%$ & 0.356 \\
\hline
\end{tabular}

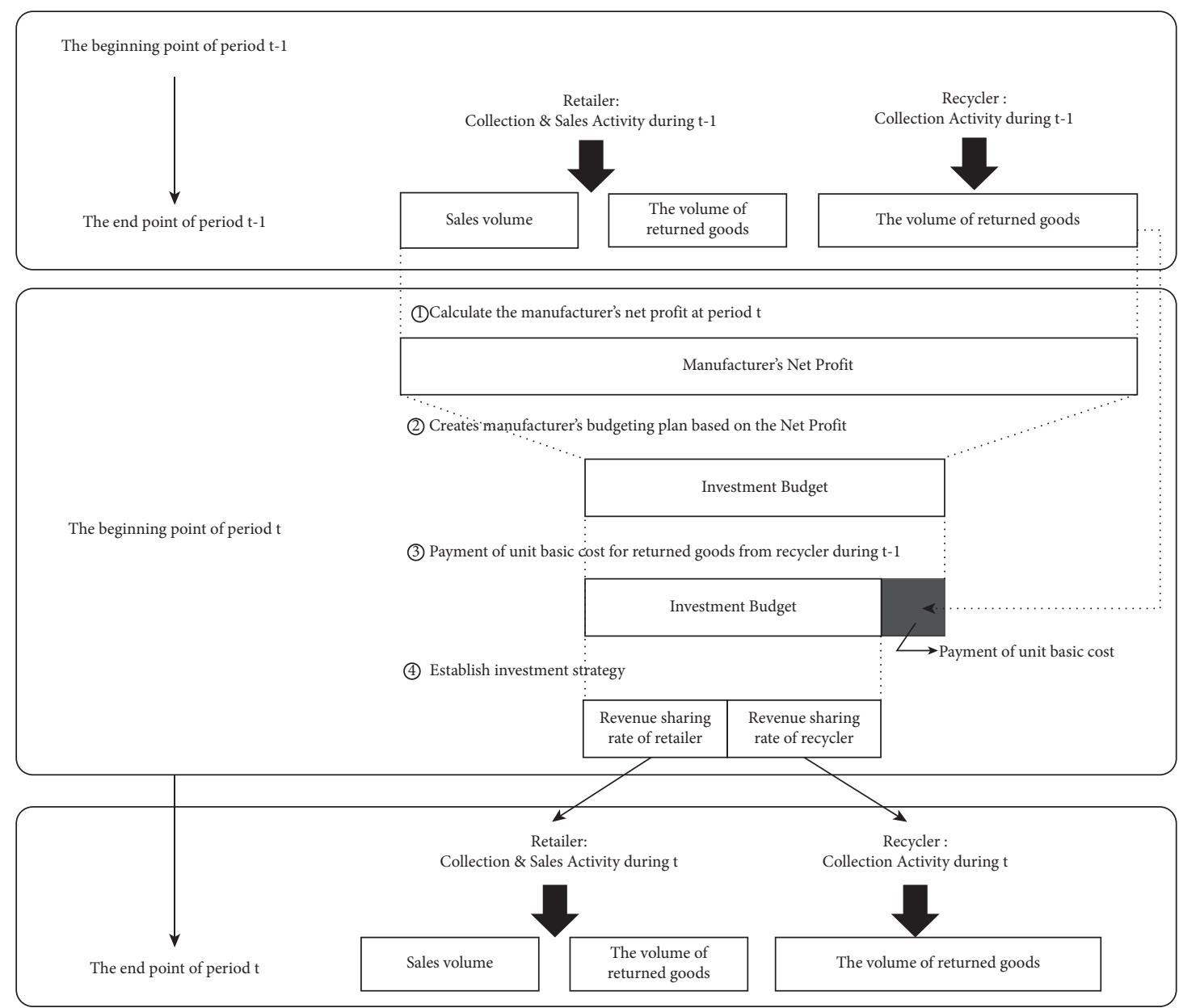

FIGURE 8: The procedure for the hybrid investment strategy.

The remainder of the amount is used to facilitate the return activity of the recycler during period $t$ by providing the investment in advance at the beginning of period $t$.

Table 4 shows the results of the hybrid strategy. Based on the implementation of this strategy, we determined the sharing ratio of both channels that maximizes the manufacturer's profit. The manufacturer's net profit is 13.34, revealing a positive effect on increasing the profits of the manufacturer compared with applying the two strategies separately. Based on the investigation of the unit investment amount for each return channel, the manufacturer paid 0.26 and 0.31 per unit return to the recycler and retailer, respectively. Although the 
TABLE 4: The results of the hybrid investment strategy $(s=0.65, k=0.6)$.

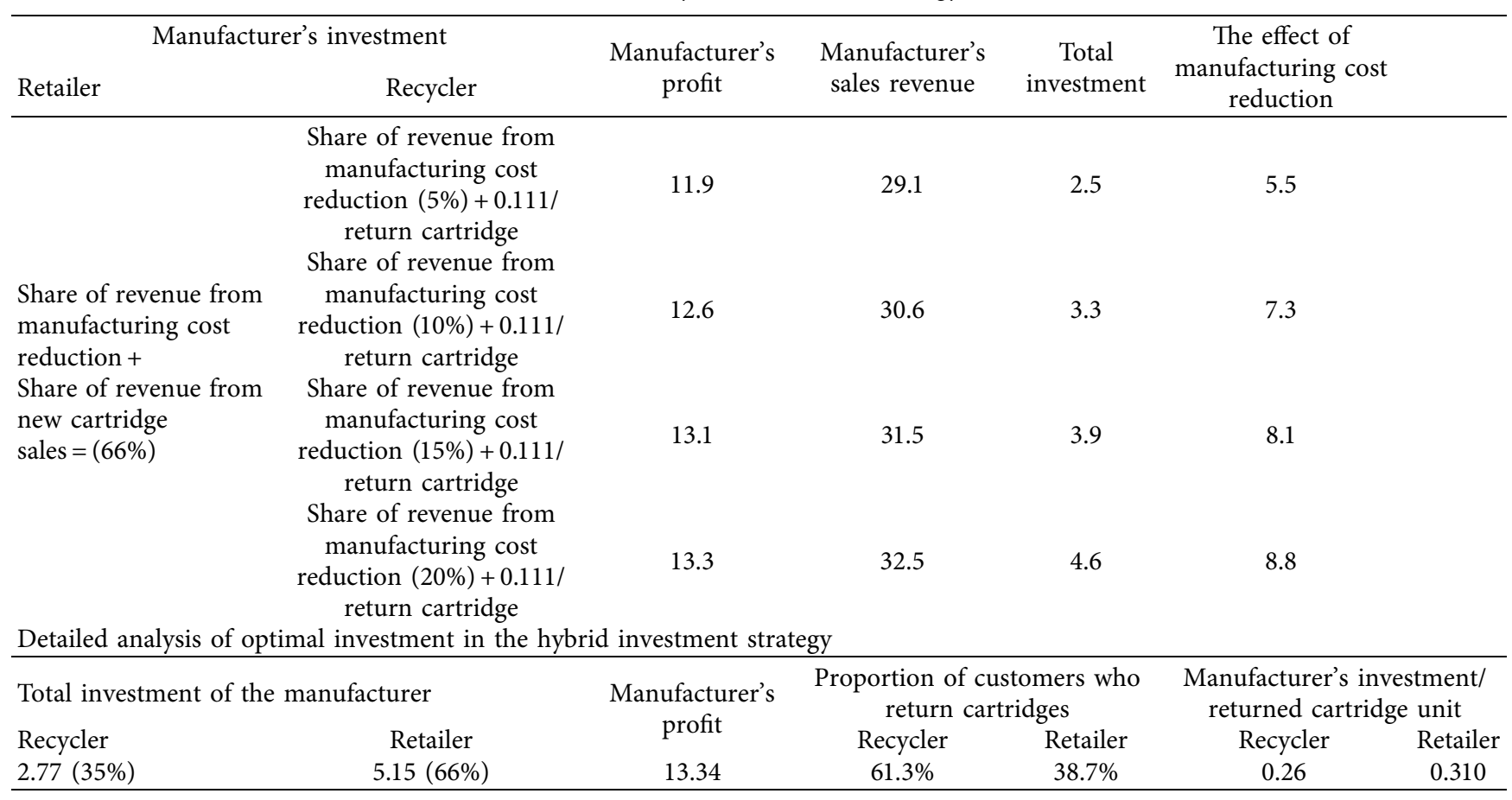

investment per unit return paid to the recycler was 0.04 , higher than under the DSURC strategy, the return rate from the recycler was higher than under the DSURC strategy. Thus, it is more effective for manufacturers to use a hybrid of the two strategies to prevent excessive investment in the recycler and to increase the return rates from both channels.

4.4. Sensitivity Analysis. Based on the previous experiments in Sections 4.1 to 4.3 , the hybrid strategy is effective in terms of increasing manufacturer profits, avoiding excess investment by the recycler, and promoting return activity through the recycler. However, since the results are only valid for the median $(s=0.65, k=0.6)$ of the two parameters, a sensitivity analysis is performed to verify that the results of the experiment are robust, even with the changes in the two parameters.

The four additional scenarios were further tested through a combination of two parameters with a minimum and maximum value in Figure 9. Case 1 has a noticeable reduction in manufacturing costs over the new sales profit effects. In Case 1, the reduced manufacturing cost effect due to remanufacturing is greater than the new sale effect ( $s$ : high, $k$ : low), and in Case 2, the manufacturing cost savings and new sales effect are significant for increasing the manufacturer's profits (s and $k$ : low). In Case 3 , the return activities of both channels have a low impact on the change in the manufacturer's profits ( $s$ and $k$ : high). Case 4 is the opposite of Case 1 ; i.e., the new sales effect generated by the retailer's return activity is great.

The results for Cases 1 and 2 show that it is more effective for the manufacturer to directly pay the appropriate subsidy to compensate the recycler for performing the return activity during the previous period and then determine the optimal sharing ratio between the two channels to allocate the remaining investment. The different investment methods in the recycler before and after the return activity could simultaneously promote the return activity and avoid excess investment in the recycler, eventually increasing the manufacturer's profits during period $t$.

Although the hybrid strategy mixing the RSI and DSURC strategies is clearly valid for increasing the return rate of the recycler during period $t$ by allocating high investment in the recycler, there is still a risk of excess investment in the recycler. Therefore, in cases where the manufacturing cost reduction effects due to the recycler's activity are greater than the cost of overinvestment in the recycler, the hybrid strategy can be applied effectively.

By contrast, in Cases 3 and 4, when the manufacturing cost saving is limited due to the small difference between the manufacturing costs and remanufacturing costs, the manufacturer should prevent excessive investment in the recycler through the return on investment per unit. That is, the manufacturer should determine the optimal amount of investment in the recycler based on the amount recovered over the previous period and adjust the sizes of investment in both channels within the confines of no excess investment.

4.5. Managerial Implication. As the importance of the recovery supply chain increases, the manufacturer leading the supply chain should make efforts to promote recovery activities through strategic partnerships with 


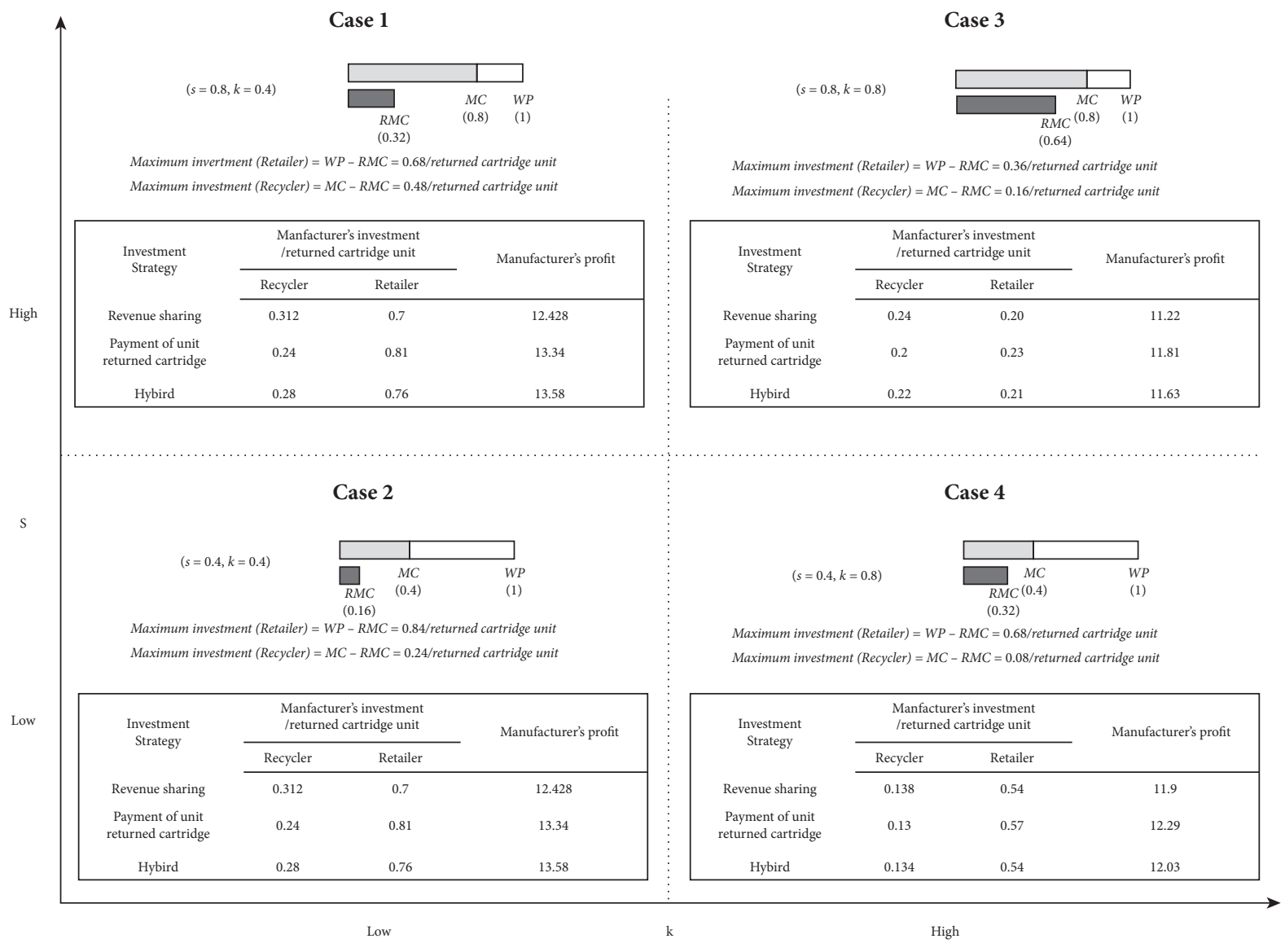

FIGURE 9: Sensitivity analysis with two parameters.

supply chain partners such as retailers or recyclers to increase its own profit. It is self-evident that the manufacturer should provide adequate compensation to recyclers and retailers participating in recovery activities to make recovery channels more active. Partners will expect the promise of appropriate compensation to precede the active implementation of recovery activities at the request of the manufacturer. Consequently, the manufacturer should establish appropriate investment strategies for profit sharing or compensation amounts through presimulation to pay compensation based on profit sharing and recovery rates. The analytical procedures and experimental analysis results presented in this study are believed to contribute to helping the manufacturer make decisions on the level of investment it can provide to prevent excessive investment in advance and enhance their partners' recovery activities.

\section{Conclusion}

This paper explores the investment strategies of the manufacturer in a CLSC comprising a single manufacturer, retailer, and recycler. We discuss how and to what extent a manufacturer should share its profits with the retailer and recycler, which have different goals and methods of collection activities. The experimental results reveal that the best investment strategy is for the manufacturer to offer differentiated payments to the retailer and recycler considering the degree of the trade-off relationship between sales profit and the manufacturing cost reduction effect. Our results have practical value by simulating a scenario-based analysis of the trade-offs a manufacturer faces in generating its own maximum revenue from sharing amounts with a retailer and a recycler collecting used products.

While this study creates a better understanding of the effects of a manufacturer's sharing strategy in a CLSC, additional analyses are needed. Extensions can add multiple partners and establish a competitive relation in attracting more used products. Additionally, to observe the real application of the proposed strategies, a sensitivity analysis that changes the unit prices (e.g., the wholesale price and retail price) and relevant unit costs in our model should be included.

\section{Data Availability}

No data were used to support this study.

\section{Conflicts of Interest}

The authors declare that they have no conflicts of interest regarding the publication of this article.

\section{Acknowledgments}

The present research has been conducted by the Research Grant of Kwangwoon University in 2020. This work was supported by the Ministry of Education of the Republic of 
Korea and the National Research Foundation of Korea (NRF-2020S1A5B8101323).

\section{References}

[1] V. D. R. Guide Jr. and L. N. Van Wassenhove, "OR FORUMthe evolution of closed-loop supply chain research," Operations Research, vol. 57, no. 1, pp. 10-18, 2009.

[2] R. C. Savaskan, S. Bhattacharya, and L. N. Van Wassenhove, "Closed-loop supply chain models with product remanufacturing," Management Science, vol. 50, no. 2, pp. 239-252, 2004.

[3] M. Schenkel, H. Krikke, M. C. J. Caniëls, and E. v. der Laan, "Creating integral value for stakeholders in closed loop supply chains," Journal of Purchasing and Supply Management, vol. 21, no. 3, pp. 155-166, 2015.

[4] A. M. Quarshie, A. Salmi, and R. Leuschner, "Sustainability and corporate social responsibility in supply chains: the state of research in supply chain management and business ethics journals," Journal of Purchasing and Supply Management, vol. 22, no. 2, pp. 82-97, 2016.

[5] R. C. Savaskan and L. N. Van Wassenhove, "Reverse channel design: the case of competing retailers," Management Science, vol. 52 , no. 1 , pp. $1-14,2006$.

[6] G. Ferrer and D. Whybark, "Material planning for a remanufacturing facility," Production and Operations Management, vol. 10, no. 2, pp. 112-124, 2001.

[7] K. Inderfurth, "Optimal policies in hybrid manufacturing/ remanufacturing systems with product substitution," International Journal of Production Economics, vol. 90, no. 3, pp. 325-343, 2004.

[8] G. C. Souza, M. E. Ketzenberg, and V. D. R. Guide, "Capacitated remanufacturing with service level constraints," Production and Operations Management, vol. 11, no. 2, pp. 231-248, 2002.

[9] L. B. Toktay, L. M. Wein, and S. A. Zenios, "Inventory management of remanufacturable products," Management Science, vol. 46, no. 11, pp. 1412-1426, 2000.

[10] F. Mafakheri and F. Nasiri, "Revenue sharing coordination in reverse logistics," Journal of Cleaner Production, vol. 59, pp. 185-196, 2013.

[11] S. Saha, S. P. Sarmah, and I. Moon, "Dual channel closed-loop supply chain coordination with a reward-driven remanufacturing policy," International Journal of Production Research, vol. 54, no. 5, pp. 1503-1517, 2016.

[12] S. Yoon and S. Jeong, "Implementing coordinative contracts between manufacturer and retailer in a reverse supply chain," Sustainability, vol. 8, no. 9, p. 913, 2016.

[13] I. E. Nielsen, S. Majumder, and S. Saha, "Game-theoretic analysis to examine how government subsidy policies affect a closed-loop supply chain decision," Applied Sciences, vol. 10, no. 1, p. $145,2020$.

[14] J.-M. Chen and C.-I. Chang, "The co-opetitive strategy of a closed-loop supply chain with remanufacturing," Transportation Research Part E: Logistics and Transportation Review, vol. 48, no. 2, pp. 387-400, 2012.

[15] K. Govindan and M. N. Popiuc, "Reverse supply chain coordination by revenue sharing contract: a case for the personal computers industry," European Journal of Operational Research, vol. 233, no. 2, pp. 326-336, 2014.

[16] G. P. Cachon and M. A. Lariviere, "Supply chain coordination with revenue-sharing contracts: strengths and limitations," Management Science, vol. 51, no. 1, pp. 30-44, 2005.

[17] T. Coltman, K. Bru, N. Perm-Ajchariyawong, T. M. Devinney, and G. R. G. Benito, "Supply chain contract evolution,"
European Management Journal, vol. 27, no. 6, pp. 388-401, 2009.

[18] S. Li, Z. Zhu, and L. Huang, "Supply chain coordination and decision making under consignment contract with revenue sharing," International Journal of Production Economics, vol. 120, no. 1, pp. 88-99, 2009.

[19] M. Seifbarghy, K. Nouhi, and A. Mahmoudi, "Contract design in a supply chain considering price and quality dependent demand with customer segmentation," International Journal of Production Economics, vol. 167, pp. 108-118, 2015.

[20] C. X. Wang, "A general framework of supply chain contract models," Supply Chain Management: An International Journal, vol. 7, no. 5, pp. 302-310, 2002.

[21] K. Govindan, H. Soleimani, and D. Kannan, "Reverse logistics and closed-loop supply chain: a comprehensive review to explore the future," European Journal of Operational Research, vol. 240, no. 3, pp. 603-626, 2015.

[22] X. Li, Y. Li, and K. Govindan, "An incentive model for closedloop supply chain under the EPR law," Journal of the Operational Research Society, vol. 65, no. 1, pp. 88-96, 2014.

[23] D. Das and P. Dutta, "A system dynamics framework for integrated reverse supply chain with three way recovery and product exchange policy," Computers \& Industrial Engineering, vol. 66, no. 4, pp. 720-733, 2013. 